\title{
Evaluation of Rutting Depth in Flexible Pavements by Using Finite Element Analysis and Local Empirical Model
}

\author{
Alaa H. Abed and Adel A. Al-Azzawi \\ Department of Civil Engineering, \\ College of Engineering, Al-Nahrain University, Baghdad, Iraq
}

Received 2012-06-22, Revised 2012-07-11; Accepted 2012-08-17

\begin{abstract}
The objective of this research is to predict rut depth in local flexible pavements. Predication model in pavement performance is the process that used to estimate the parameter values which related to pavement structure, environmental condition and traffic loading. The different local empirical models have been used to calculate permanent deformation which include environmental and traffic conditions. Finite element analysis through ANSYS computer software is used to analyze two dimensional linear elastic plane strain problem through (Plane 82) elements. Standard Axle Load (ESAL) of 18 kip $(80 \mathrm{kN})$ loading on an axle with dual set of tires, the wheel spacing is $13.5 \mathrm{in}(343 \mathrm{~mm})$ with tire contact pressure of $87 \mathrm{psi}(0.6 \mathrm{MPa})$ is used. The pavement system is assumed to be an elastic multi-layers system with each layer being isotropic, homogeneous with specified resilient modulus and Poisson ratio. Each layer is to extend to infinity in the horizontal direction and have a finite thickness except the bottom layer. The analysis of results show that, although, the stress level decrease $14 \%$ in the leveling course and $27 \%$ in the base course, the rut depth is increased by 12 and $28 \%$ in that layers respectively because the material properties is changed.
\end{abstract}

Keywords: Finite Elements, Flexible Pavements, Linear Elastic, Rutting

\section{INTRODUCTION}

The evaluation of asphalt concrete mixes for their tendency to rutting has been an important research field for many years. The ability to predict the amount and growth of permanent deformation or rutting in flexible pavements is an important aspect of pavement design. Finite Element (FE) techniques can be successfully used to simulate different pavement problems that could not be modelled using the simpler multi-layer elastic theory.

Rutting is a main distress encountered in asphalt pavements, especially when the temperature is high as in Iraq climate during the summer months. Rutting is caused by the accumulation of permanent deformation in all pavement layers under the action of repeated traffic loading. Among the contributions of rut depth by the various pavement layers, the cumulative permanent deformation in the surface course of asphalt pavement is known to be responsible for a major portion of the final rut depth measured on the pavement surface. So, rutting occurs only on flexible pavements, as indicated by the permanent deformation or rut depth along the wheel paths.

The width and depth of the rut are widely affected by structural characters of the pavement layers (thickness and material quality), traffic loads and environmental conditions (Huang, 2003).

The objective of this study is to predict rutting of asphalt pavement using different local models. The numerical analysis of the pavement layer is based on the finite element method. Table 1 shows the material properties of the layers that adopted in this case study.

Table 1. Material properties for road layers

\begin{tabular}{lcc}
\hline Layer & $\begin{array}{l}\text { Modulus of } \\
\text { Elasticity }(\mathrm{E})\left(\mathrm{N} / \mathrm{mm}^{2}\right)\end{array}$ & $\begin{array}{l}\text { Poisson's } \\
\text { ratio }(\sqrt{ })\end{array}$ \\
\hline Surface & 2689 & 0.350 \\
Binder & 2206 & 0.350 \\
Base coarse & 1655 & 0.350 \\
Subbase & 110 & 0.400 \\
Subgrade & 35 & 0.499 \\
\hline
\end{tabular}




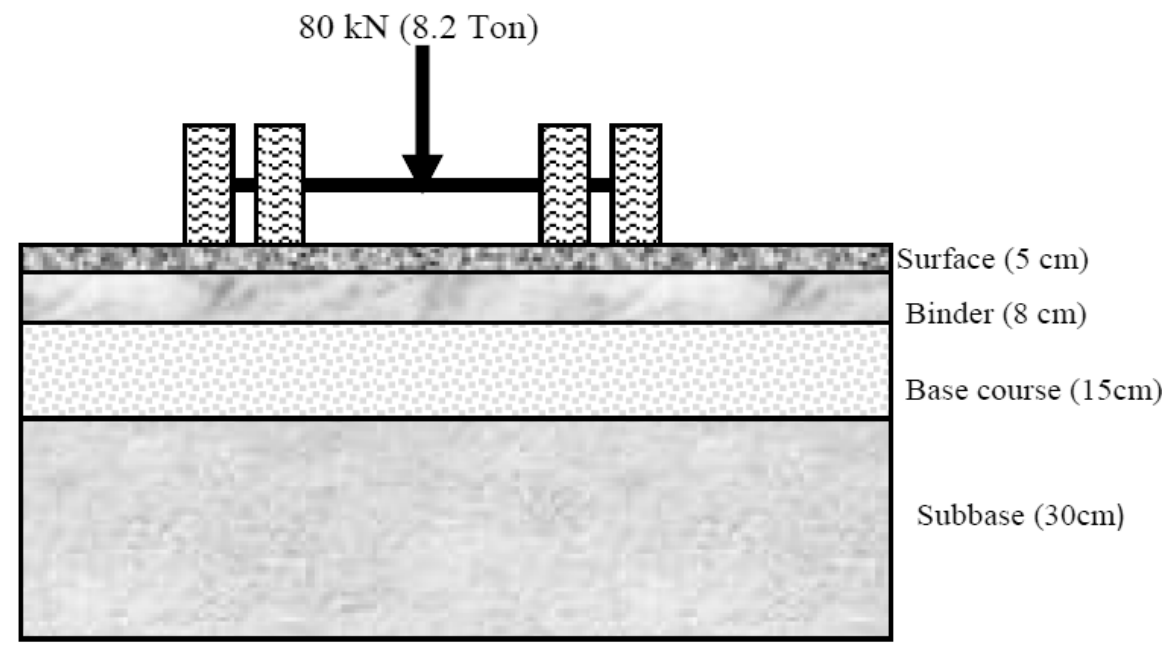

Fig. 1. Pavement design due to rutting criterion

The pavement structure analysis is performed using ANSYS software package. The importance of this research arises from the fact that several agencies adopted the rutting as a failure criterion in the pavement design. Almost all of these methods assumed a relation between the stress- strain and the following response of the pavement structure. The critical case is the stress and strain at the centre of the vertical axis of the load, calculated at this point as shown in Fig. 1.

\section{MATERIALS AND METHODS}

\subsection{Finite Element Modelling}

FEA has been proven suitable for application to complex pavement problems. Although using three Dimensional (3D) finite element models can solve all problems that can be solved with two-Dimensional (2D) models, it is very expensive to use $3 \mathrm{D}$ models in terms of data preparation and computational time. The pavement structure has a large longitudinal dimension, which makes it suitable for using 2D plane strain models when studying transverse profiles. Hua (2000) compared the FEA results of pavement rutting using a plane strain model versus a 3D model. The predicted surface profiles of $2 \mathrm{D}$ and $3 \mathrm{D}$ models under 5000 wheel passes were given. It can be seen from the previous research that there is no significant difference between the two models. The difference in maximum rut depths from the two models is less than $2 \%$. Therefore, 2D plane strain models were appropriate for this study.

In this research, the finite element mesh, geometric characteristics, boundary conditions, material properties and loading conditions were used for all analyses in the simplified models. The 8-node, quadrilateral plane strain element from the ANSYS two-dimensional, solid-element library (PLANE82) was selected for use in the analysis. All elements were 8 nodes quadratic to improve the level of accuracy. A series of finite element analyses was performed with decreasing the element size to determine the suitable mesh size. The mesh was a fine mesh around the loading area along the wheel path and a relatively coarse mesh was used far away from the loading area in vertical and horizontal directions. The total number of elements in the mesh was 5727. Figure 2 and 3 show element types, mesh size and loading.

The bottom surface of the subgrade is assumed to be fixed, which means that nodes at the bottom of the subgrade cannot move horizontally or vertically. The boundary nodes along the pavement edges are horizontally constrained, but are free to move in the vertical direction as shown in Fig. 2.

Plane strain model is used in this study. A plane strain model assumes that the thickness in the horizontal plane is infinite. Geometry in the horizontal plane does not change so that strain is zero. Loading is assumed as a strip extending infinitely in the horizontal plane as shown in Fig. 3. The pavement cross section of the studied road is simulated by using a 2D plane strain finite element model. The model consists of an asphalt pavement layers (wearing, binder and base) the thicknesses of these layers are shown in Fig. 1. Based on the assumption that there is no deformation beyond a certain depth in the subgrade the depth of the subgrade was fixed at $3.60 \mathrm{~m}$. The width of the model was selected to reduce any edge effect errors and when the effects of boundaries become negligible, so it was set at $7.20 \mathrm{~m}$. 


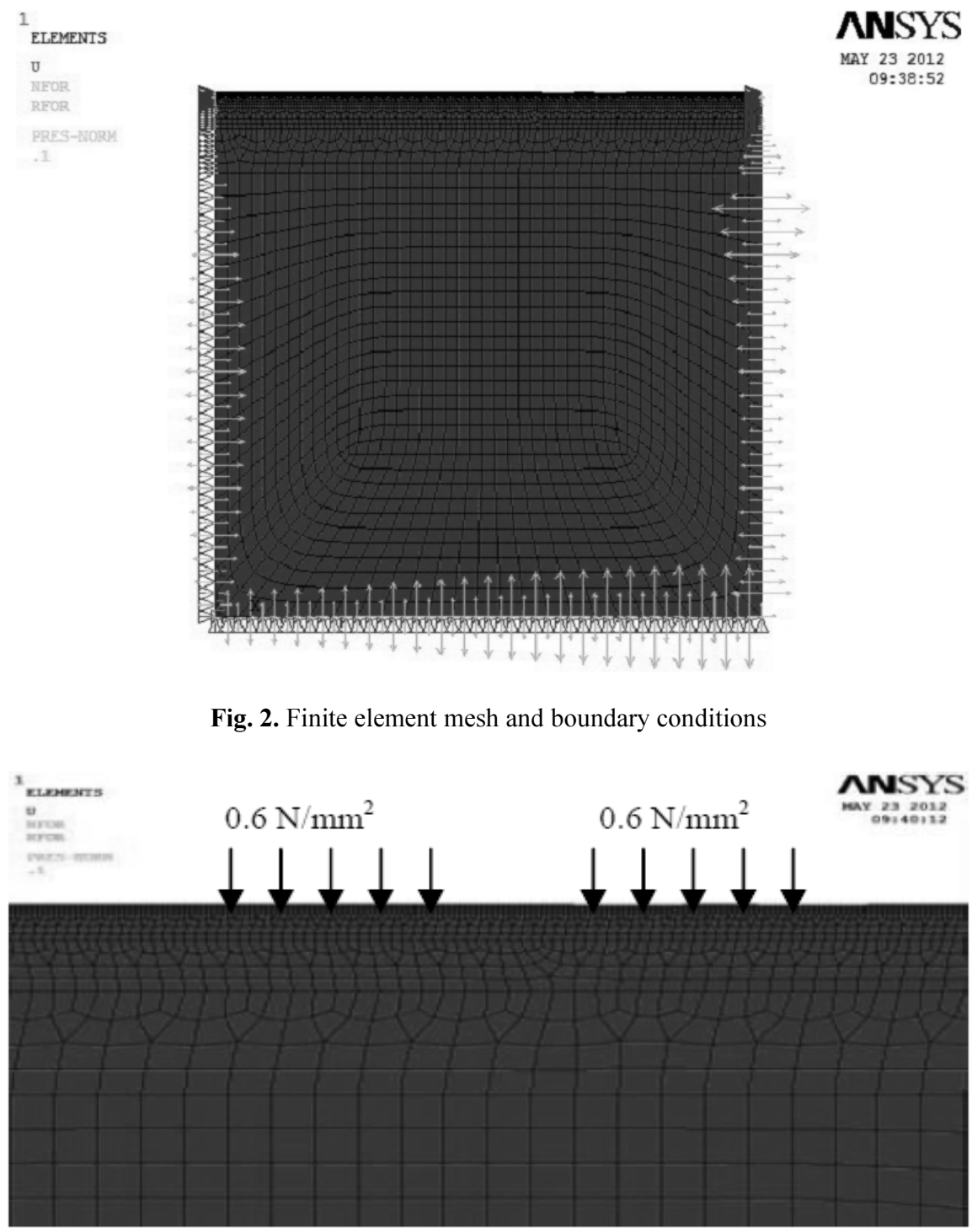

Fig. 3. Pressure loadings (tires) and road layer elements

\subsection{Permanent Deformation}

Asphalt binders are rheological materials; that is, their behavior depends on temperature and rate (or time) of loading, at any combination of time and temperature, the time-dependent (i.e., viscoelastic) behavior of asphalt binders, within the linear range, is best characterized by two properties: The total resistance to deformation under load and the relative distribution of that deformation between elastic and viscous parts (Bahia and Anderson, 1995). Ruts are depressions which occur in the pavement's wheel path as a result of traffic loads. The most common recent cause of rutting is associated with the HMA layer, especially on routes with heavy loads and high tire pressures; much of this rutting is attributed to improper mix design. Some of the most common mistakes when designing heavy duty HMA mixtures are, selection of an asphalt content that is too high, use of excessive filler material (minus 200 material); and use of too many rounded particles in both coarse and fine aggregates in the HMA, the singly largest contributor to rutting in HMA is excessive asphalt content. Rutting resulting from accumulation of permanent deformation in the asphalt layer is now 
considered to be the principal component of flexible pavement rutting. Permanent deformation in asphalt layers is caused by an asphalt mixture that is too low in shear strength to resist the repeated heavy loads to which it is subjected. Asphalt pavement rutting from weak asphalt mixtures is a high temperature phenomenon, it most often occurs during the summer when high pavement temperatures are evident. Mixture factors that causing rutting including: (1) aggregate gradation, (2) aggregate absorption, (3) aggregate affinity for asphalt, (4) aggregate size, (5) coarse aggregate shape, (6) coarse aggregate texture, (7) fine aggregate shape (angularity), (8) mineral filler properties, (9) asphalt content, (10) performance grading, (11) plastic fines in the fine aggregate, (12) low air voids and (13) performance graded asphalts (Kirkner et al., 1996).

\subsection{Local Rutting Models}

Predication model in pavement performance is the process that used to estimate the parameter values which related to pavement structure, environmental condition and traffic loading. Many local models are developed for predicting permanent deformation, (Yassoub, 2005) predict the following model Eq. 1:

$\varepsilon_{\mathrm{vp}}=4.7195 \times 10^{-9} \times \sigma^{0.868} \times \mathrm{t}^{0.658}$
$\times \mathrm{T}^{1.974} \log \varepsilon_{\mathrm{p}}(\mathrm{N})=\log \varepsilon_{\mathrm{vp}}+\mathrm{S} \log \mathrm{N}$

Where:

$\varepsilon_{\mathrm{VP}}=$ Visco-plastic strain

$\sigma=$ Level of applied stress

$\mathrm{t}=$ Time of loading and

$\mathrm{T}=$ Degree of temperature

The developed form of the accumulated permanent strain as a function of the number of repetitions. Albayati (2006) developed rutting model as presented below Eq. 2:

$$
\begin{aligned}
& \mathrm{LE}_{\mathrm{p}}=-34.463+0.983 \log \mathrm{N}^{(0.00973 \mathrm{~T}+0.00284 \mathrm{~S})} \\
& +1.961 \log \mathrm{T}+1.812 \log \mathrm{S}+0.656 \log \mathrm{D} \\
& -36.277 \log \mathrm{B} 4.951 \log \mathrm{F}-1.455 \log \mathrm{A}-1.93 \log \mathrm{M}
\end{aligned}
$$

Where:

$\mathrm{LE}_{\mathrm{P}}=\mathrm{Log}$ of accumulated permanent micro-strain at $\mathrm{N}$ load repetition

$\mathrm{N}=$ Load repetition

$\mathrm{T}=$ Test temperature in degree centigrade $\left({ }^{\circ} \mathrm{C}\right)$

$\mathrm{S}=$ Stress level (psi)

$\mathrm{D}=$ Applied stress duration (sec)

$\mathrm{B}=$ Percent absorbed asphalt (by weight of aggregate)

$\mathrm{A}=$ Percent air voids

$\mathrm{M}=$ Percent voids in the mineral aggregate
$\mathrm{F}=$ Voids filed with asphalt and $\mathrm{E}=$ percent effective asphalt (by volume of mix)

Abed (2010) studied the effects of loading, temperature and material properties on the permanent deformation by developing the following model Eq. 3:

$\varepsilon_{\mathrm{P}}=3.365 \times 10^{-10} \times \mathrm{N}^{0.532} \times \mathrm{T}^{1.798} \times \sigma^{0.838} \times \eta^{-0.672} \times \mathrm{A}_{\mathrm{c}}^{0.448}$

Where:

$\mathrm{T}=$ Test temperature in degree centigrade $\left({ }^{\circ} \mathrm{C}\right)$,

$\Sigma=$ Stress level (psi),

$\mathrm{H}=$ Viscosity at $135^{\circ} \mathrm{C}(\mathrm{Pa} . \mathrm{S})$,

Ac $=$ Asphalt content $(\%)$,

$\mathrm{N}=$ Number of repetition,

$\varepsilon_{\mathrm{p}}=$ Permanent plastic strain at load repetition (N)

Hilal (2011) studied the effects of permanent strain and elastic modulus by developing the following Eq. 4:

$\varepsilon_{\mathrm{P}}=3691\left(10^{-5.127} \times \mathrm{T}^{1.463} \times \mathrm{N}^{0.684}\right) \times \varepsilon_{\mathrm{r}}$

Where:

$$
\varepsilon_{\mathrm{r}}=10^{-14.425} \times \mathrm{T}^{5.079} \times \mathrm{P}_{\mathrm{s}}^{2.528}
$$

Where:

$\varepsilon_{\mathrm{P}}=$ Predicted vertical plastic strain,

$\mathrm{T}=$ Temperature $\left({ }^{\circ} \mathrm{C}\right)$,

$\mathrm{N}=$ Number of load repetition,

$\varepsilon_{\mathrm{r}}=$ Computed vertical resilient strain,

$\mathrm{P}_{\mathrm{s}}=$ Asphalt content (\%),

$\eta=$ Asphalt binder viscosity (Pa.sec) and

$\sigma=$ Stress level (psi)

\subsection{Traffic Loading and Temperature}

Traffic data are key inputs for the analysis and design of pavement structures. AASHTO (1993) design guides design guides usually was used for the analysis or design of the traffic quantify in terms of Equivalent Single Axle Loads (ESAL). The total estimation or projected magnitude of the various traffic loadings are converted to the total number of passes of the equivalent standard axle loading, usually the Equivalent $80-\mathrm{kN}$ (18-kip) Single Axle Load (ESAL). The total number of ESAL is used as the traffic loading input for analysis and design of the pavement structure.

Table 2. Mid-Depth Layer Temperature

\begin{tabular}{lcccr}
\hline Layer & Tair & Lat & $\begin{array}{l}\text { Mid depth } \\
\text { H }(\mathrm{mm})\end{array}$ & \multicolumn{1}{c}{$\begin{array}{l}\text { Temp. } \\
\left({ }^{\circ} \mathrm{C}\right)\end{array}$} \\
\hline Wearing & 37.0 & 33.23 & 25 & 55 \\
Leveling & 37.0 & 33.23 & 90 & 49 \\
Base & 37.0 & 33.23 & 205 & 45 \\
\hline
\end{tabular}


The traffic to be used for design is the average traffic during the design period, so the initial traffic must be multiplied by a growth factor. The temperature data are significant variable in the analysis of rutting in the asphalt concrete layers of the flexible pavement especially in hot climates. Extensive temperature data are available from the Iraqi Metrological Organization. For Baghdad, the mean high air temperature is $37^{\circ} \mathrm{C}$. The temperature at mid depth of each layer was founded according to the Long Term Pavement Performance (LTPP) equation that shown below Eq. 5:

$$
\begin{aligned}
& \mathrm{T}_{\mathrm{pav}}=54.32+0.78 \mathrm{~T}_{\text {air }}--0.0025 \mathrm{Lat}^{2} \\
& -15.14 \times \log _{10}(\mathrm{H}+25)+\mathrm{Z}\left(9+0.16 \mathrm{~S}_{\mathrm{d}}^{2}\right)^{0.5}
\end{aligned}
$$

Where:

$\mathrm{T}_{\mathrm{pav}}=$ High asphalt concrete pavement temperature below surface

$$
\begin{aligned}
{ }^{\circ} \mathrm{C}, \mathrm{T}_{\text {air }}= & \text { High air temperature, }{ }^{\circ} \mathrm{C}, \text { Lat Latitude of the } \\
& \text { section, degrees, } \\
= & \text { Depth to surface, mm } \\
\mathrm{H}= & \text { Standard deviation of the high } 7 \text { day mean air } \\
& \text { temperature, } \\
\mathrm{S}_{\mathrm{d}} & \\
{ }^{\circ} \mathrm{C}, \mathrm{Z}= & \text { Standard normal distribution table } \\
\mathrm{Z} & =2.055 \text { for } 98 \% \text { reliability }
\end{aligned}
$$

The temperatures at the mid-depth of each asphalt concrete layer corresponding to high air temperature of $37^{\circ} \mathrm{C}$ are shown in Table 2; note that Lat $=33.23$ and $\mathrm{Z}$ $=0$ for $50 \%$ reliability.

\section{RESULTS}

The results analysis of the principle stresses, vertical stress and the vertical displacements for the case of surface layer thickness of $5 \mathrm{~cm}$ are shown in Fig. 4-7.

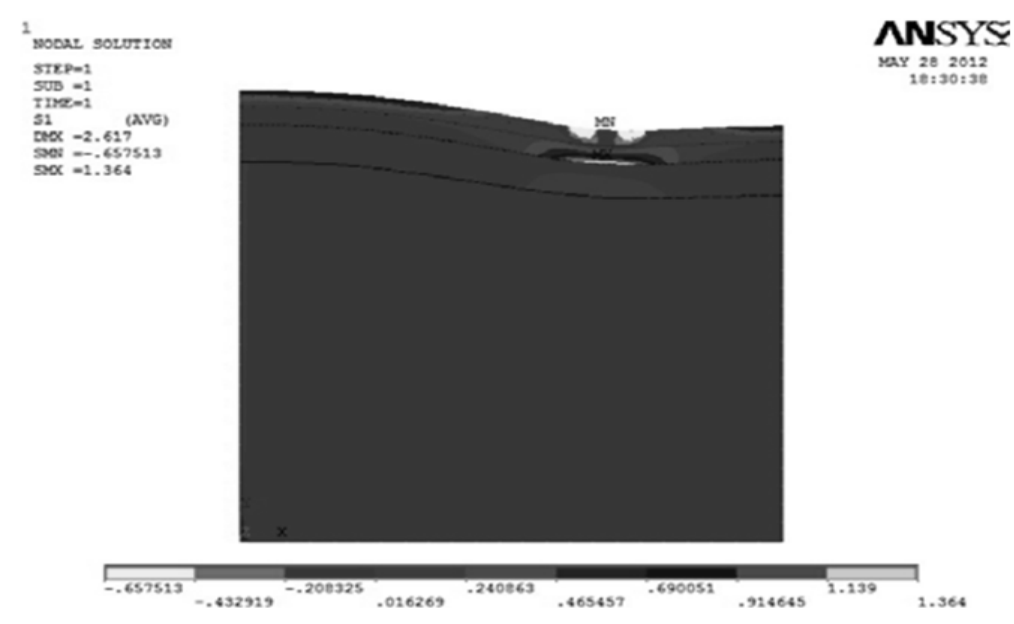

Fig. 4. First principal stress in $\mathrm{N} / \mathrm{mm}^{2}$

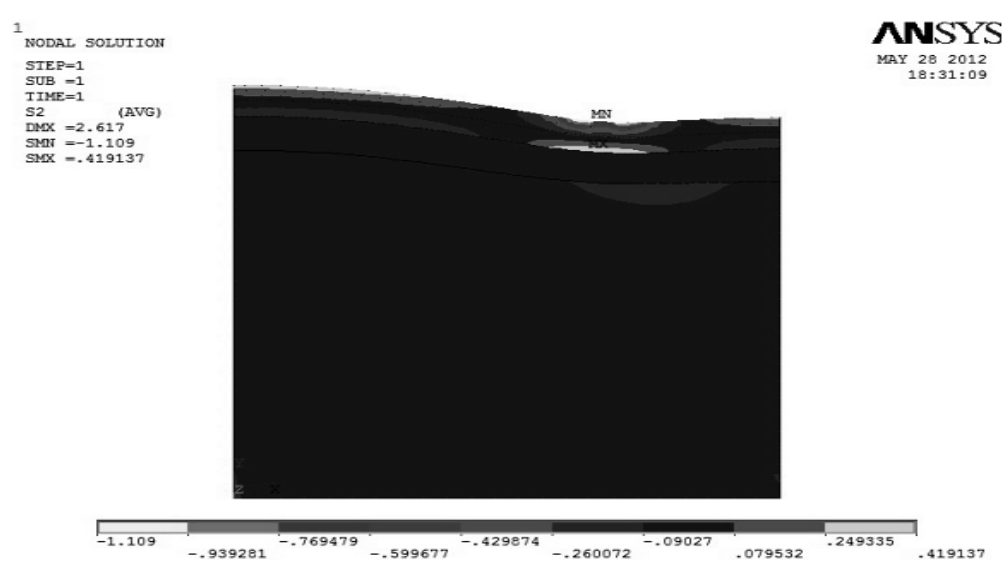

Fig. 5. Second principal stress in $\mathrm{N} / \mathrm{mm}^{2}$ 
Alaa H. Abed and Adel A. Al-Azzawi / American Journal of Engineering and Applied Sciences 5 (2) (2012) 163-169

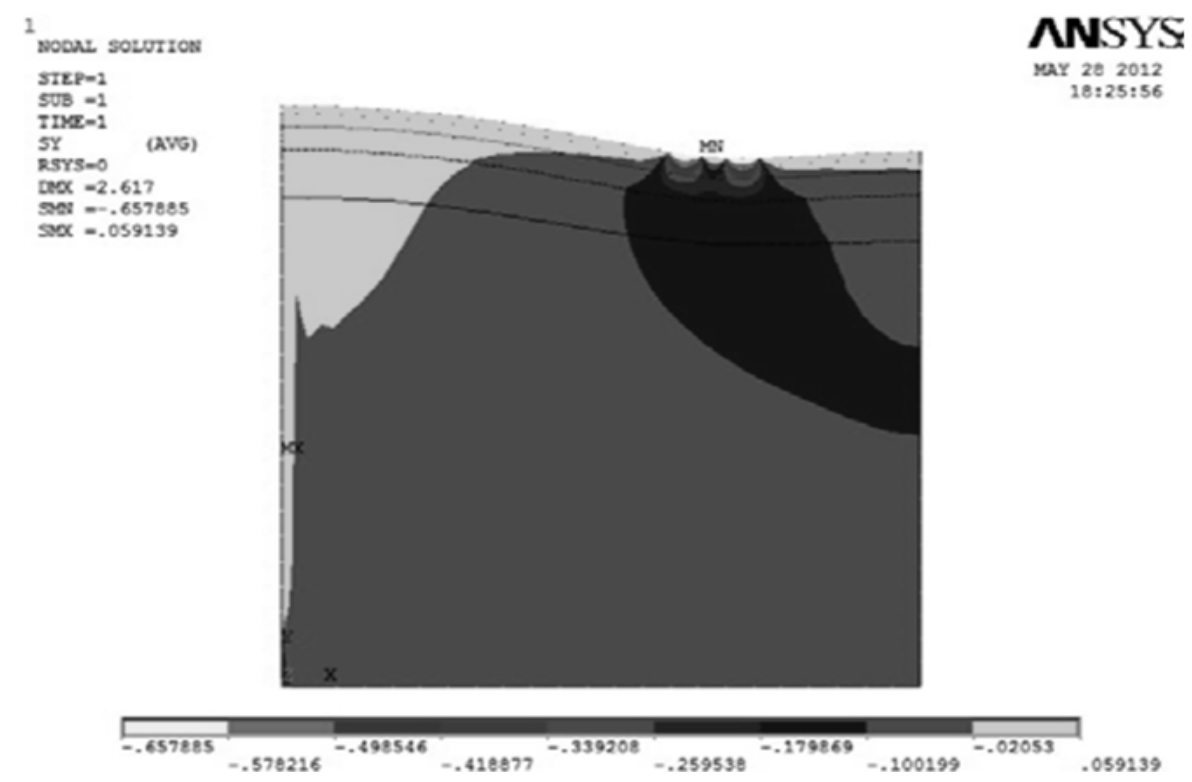

Fig. 6. Vertical normal stress in $\mathrm{N} / \mathrm{mm}^{2}$

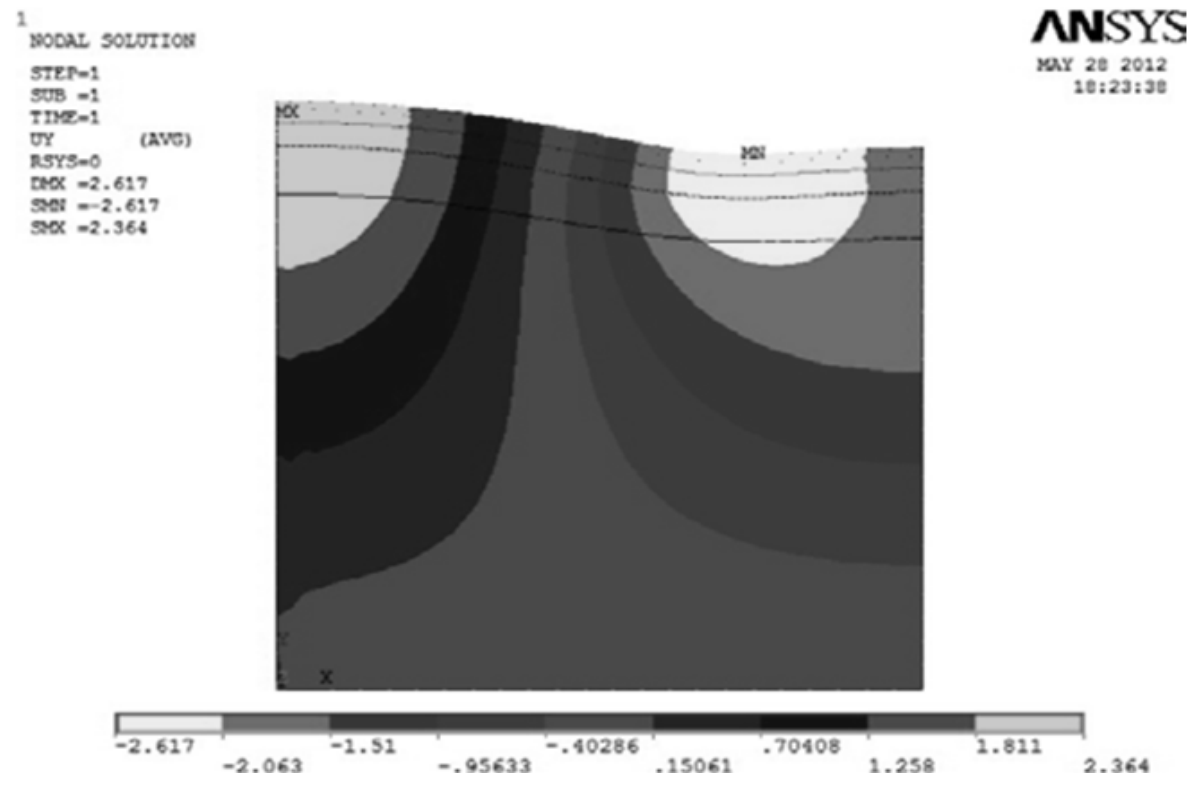

Fig. 7. Vertical displacement in $\mathrm{mm}$

Table 3. Input parameters and rut depth for each asphalt concrete layer

\begin{tabular}{lcllllllr}
\hline Layer & $\begin{array}{l}\text { N Esal } \\
\times 10^{6}\end{array}$ & $\begin{array}{l}\text { Temp. } \\
\left({ }^{\circ} \mathrm{C}\right)\end{array}$ & $\begin{array}{l}\text { Ac } \\
(\%)\end{array}$ & $\begin{array}{l}\eta \\
\text { Pa.S }\end{array}$ & $\begin{array}{l}\sigma \\
\text { Psi }\end{array}$ & $\varepsilon_{\mathrm{r}}$ & $\varepsilon_{\mathrm{p}}$ & $\begin{array}{l}\text { Rut } \\
\text { depth }(\mathrm{mm})\end{array}$ \\
\hline Wearinf & 2.900 & 55.000 & 4.6 & 0.516 & 84 & -0.000 & 0.156 & 7.781 \\
Leveling & 2.900 & 49.000 & 4.2 & 0.516 & 72 & -0.000 & 0.109 & 8.732 \\
Base & 2.900 & 45.000 & 3.9 & 0.516 & 61 & 2.6179 & & 9.993 \\
& & & & & & E-04 & 0.067 & 26.505 \\
Total & & & & & & & & \\
\hline
\end{tabular}


The distribution of vertical stress with depth is shown in the Fig. 6. Table 3 shows the values of stress which was chosen at mid depth of each asphalt concrete layer.

Table 3 shows the input parameters that have been used in the third model for wearing and levelling layers and forth model for base layer in order to determine the rut depth in each asphalt concrete layer and to calculate the total rut depth.

\section{DISCUSSION}

The finite element model developed for rutting analysis in flexible pavement give a good indication to find the distribution of stress in the pavement layers. The fine finite element mesh used in this study gives the values of stresses and strains in each point with higher accuracy. The stress have larger values near the applied load where larger deformations occur.

\section{CONCLUSION}

The stress parameter obtained in each layer from finite element analysis is used in local emprical models for finding the rut depth. Although, the stress level decreased by $14 \%$ in the leveling course and $27 \%$ in the base course, the rut depth increased by $12 \%$ and $28 \%$ in that layers respectively because the material properties is changed.

\section{REFERENCES}

AASHTO, 1993. AASHTO Guide for Design of Pavement Structures. 1st Edn., AASHTO, Washington, D.C., ISBN-10: 1560510552, pp: 640.
Abed, A. H., 2010. Required Criteria for Implementation of the Superpave System in Local Pavement Design. 1st Edn., University of Baghdad, Iraq, pp: 189.

Albayati, A., 2006. Permanent Deformation Prediction of Asphalt Concrete Under Repeated Loading. University of Baghdad, Iraq, pp: 129.

Bahia, H.U. and D.A. Anderson, 1995. The New Proposed Rheological Properties of Asphalt Binders: Why are They Required and How do They Compare to the Conventional Properties. In: Physical Properties of Asphalt Cement Binders, Hardin, J.C., (Ed.). ASTM International, Philadelphia, ISBN-10: 0803119887, pp: 1-27.

Hilal, M.M., 2011. Prediction Of Permanent Deformation Models for Asphalt Pavements in Hot Climates. 1st Edn., University of Baghdad, Iraq, pp: 80.

Hua, J., 2000. Finite element modeling and analysis of accelerated pavement testing devices and rutting phenomenon. Purdue University.

Huang, Y.H., 2003. Pavement Analysis and Design. 2nd Edn., Prentice Hall, Englewood Cliffs, New Jersey, USA., ISBN-10: 0131424734, pp: 792.

Kirkner, D.J., W. Shen, M.I. Hammons and M.D. Smith, 1996. Numerical simulation of permanent deformation in flexible pavement systems subjected to moving loads. Proceedings of the 11 th Conference on Engineering Mechanics, May 19-22, Fort Lauderdale, FL; USA., pp: 430-433.

Yassoub, N., 2005. Prediction Model of Rutting Potential in Flexible Pavements. 1st Edn., University of Baghdad, Iraq, pp: 66. 